\title{
Cross-sectional TEM Analysis of Porcelain Fused to Gold-coated Titanium
}

\author{
Yasuhiro TANAKA ${ }^{1}$, Ikuya WATANABE ${ }^{2}$ and Toru $\mathrm{OKABE}^{2}$ \\ ${ }^{1}$ Department of Advanced Materials Science, Faculty of Engineering, Kagawa University, 2217-20 Hayashi, Takamatsu, 761- \\ 0396, Japan \\ ${ }^{2}$ Department of Biomaterials Science, Baylor College of Dentistry, Texas A\&M University System Health Science Center, \\ 3302 Gaston Ave, Dallas, TX 75246, USA \\ Corresponding author, Ikuya WATANABE; E-mail: iwatanabe@bcd.tamhsc.edu
}

Received June 27, 2006 /Accepted October 13, 2006

This study investigated the interfacial microstructure between gold-coated titanium and low-fusing porcelain. The square surfaces of cast titanium split rods were sputter-coated with gold using a sputter coater at $40 \mathrm{~mA}$ for 1,000 seconds. Specimens were prepared for transmission electron microscopy (TEM) by cutting and polishing two pieces of the gold-coated split-rod specimens, which were glued and embedded in $\mathrm{Cu}$ tubes with an epoxy adhesive. TEM observation was also conducted for the gold-coated specimens after degassing and porcelain fusing. Due to the gold coating, intermetallic compounds of $\mathrm{Au}$-Ti formed under the sputtered gold layer after degassing and porcelain fusing. $\mathrm{Ti}_{3} \mathrm{Au}$ and $\mathrm{Ti}_{3} \mathrm{Al}$ layers were also observed beneath the Au-Ti intermetallic compound layer. There was good adhesion of porcelain to the Au-Ti compound and Ti oxides without any gaps or formation of a Ti-deficient intermediate layer, which is normally observed at the titaniumporcelain interface. The results of this TEM study suggested that gold-sputter-coating the cast titanium surface produced a Ti-Au intermetallic compound and suppressed the formation of a Ti-deficient intermediate layer, resulting in improved adherence between porcelain and titanium.

Keywords: TEM, Titanium-porcelain interface, Gold coating

\section{INTRODUCTION}

Titanium and its alloys are commonly used as biomaterials in the medical and dental fields due to their excellent corrosion resistance and biocompatibility. Current applications include artificial hip joints, orthodontics wires, removable denture frameworks, and dental implants depending on the characteristics of each alloy. One of the dental applications of titanium is porcelain-fused-to-metal (PFM) restorations for crowns and fixed partial dentures ${ }^{1,2}$. However, the bond strengths of porcelain-fused-totitanium are reported to be weaker than those of porcelain fused to conventional dental alloys due to the following: (1) the lower thermal expansion coefficient of titanium compared to porcelain; and (2) the highly oxidized titanium surface at higher fusing temperature ${ }^{2,3)}$. Nonetheless, with the development of low-fusing porcelain with a low thermal expansion coefficient (similar to that of titanium) and baking technique (degassing, fusing temperature, soaking time, heat rate, etc.), the bond strengths between porcelain and titanium have somewhat improved.

Many studies have been conducted to investigate the bonding of porcelain to titanium ${ }^{4-15)}$. Delamination of porcelain from titanium was reported to take place at the weak interfacial reaction layers between the baked porcelain and the oxidized titanium surface $^{2)}$. Using porcelain-fused-to-titanium specimens marked with $\mathrm{Au}$ at their interface and analyzed with SEM-EDX, Miura et $a l^{13)}$ reported that delamination at the interface between titanium and porcelain created an oxygen-dissolved titanium and/ or titanium oxide phase that diffused to the porcelain side. In our transmission electron microscopy (TEM) studies of the porcelain-titanium interface ${ }^{14,15}$, compounds of amorphous titania (titanium dioxide) and titanium with a considerable concentration of dissolved oxygen existed as a Ti-deficient intermediate layer on the titanium side, whereas low-valence titanium oxides ( $\mathrm{TiO}$ and $\mathrm{Ti}_{2} \mathrm{O}_{3}$ ) were detected on the porcelain side. The intermediate layer at the titanium side was considered to be the cause of cohesive failure at their interface.

One of the methods of improving the weak bonding of porcelain to titanium is gold-coating the titanium surface ${ }^{16,17)}$. Lee et $a l^{16)}$ reported that upon determining the area fraction of adherent porcelain (AFAP\%) from SEM/EDX observation of the porcelain remaining after biaxial flexure testing, improved porcelain adherence to gold sputter-coated titanium was clearly gained. The AFAP value for the goldcoated cast titanium (42.6\%) was significantly higher than that of the non-coated control specimens (13.5\%). Likewise, using SEM/EDX analysis, Miura et $a{ }^{177}$ observed the cross-sectional microstructure of porcelain-fused titanium coated with a gold-sputtered layer. It was reported that the thickness of the interfacial reaction layers and the depth of titanium diffusion decreased because of gold sputter coating. Moreover, gold sputtering changed the microstructure of the layer, which resulted in improved adherence between the titanium and porcelain.

The present study conducted high-resolution 
transmission electron microscopy (HRTEM) analysis to investigate the cross-sectional microstructure of the interface between porcelain and gold sputtercoated titanium and to clarify the interfacial microstructural changes induced by gold sputtering.

\section{MATERIALS AND METHODS}

\section{Materials}

Split-rod wax patterns $(2.2 \mathrm{~mm}$ diameter $\times 10 \mathrm{~mm}$ length; Ready Casting Wax, GC Corp., Tokyo, Japan) were used to cast commercially pure titanium (ASTM Grade 2, Titanium Ind., Grand Prairie, TX, USA) using a magnesia-based investment (Selevest $\mathrm{CB}$, Selec Co., Osaka, Japan) and a centrifugal titanium casting machine (Ticast Super R, Selec Co.). After casting, the cast titanium split rods were ultrasonically cleaned with acetone for 30 minutes. Air abrasion was not performed since it would produce rough surfaces that might interfere with the identification of the interface between the porcelain and cast titanium surface. However, surfaces of titanium cast with magnesia-based investment are smooth and highly integrated with a reduced reaction layer, and such surfaces are suitable for TEM investigation.

\section{Surface treatment processes}

The cast titanium surfaces (C) were treated using three processes: (1) gold sputter coating (hereafter, $C G)$; (2) gold sputter coating (G) + degassing (D), (hereafter, CGD); and (3) gold sputter coating (G) + degassing (D) + porcelain fusing (P) (hereafter, CGDP). The $2.2 \times 10 \mathrm{~mm}$ square surfaces of the cast titanium split rods were sputter-coated with gold using a sputter coater (Desk II Cold Sputter/Etch Unit, Denton Vacuum, Moorestown, NJ, USA) at 40 $\mathrm{mA}$ for 1,000 seconds. Degassing was conducted in a dental porcelain furnace (Centurion Q200, DegussaNey Dental, Yucaipa, CA, USA). The specimens were put in the furnace preheated at $550^{\circ} \mathrm{C}$, heated to 800 ${ }^{\circ} \mathrm{C}$ at a heating rate of $55^{\circ} \mathrm{C}$ under a vacuum level of $27 \mathrm{kPa}$, held at $800^{\circ} \mathrm{C}$ for 60 seconds, and then cooled in ambient air.

For the CGDP samples, bonding porcelain (approx. 0.1-mm thick) was applied to the degassed titanium surface and fused in the furnace heated to $790^{\circ} \mathrm{C}$.

\section{Disk specimens}

Two CG, CGD, or CGDP split-rod samples were glued to each other and embedded in $\mathrm{Cu}$ tubes with an epoxy adhesive (G-1 epoxy, Gatan, CA, USA). Disk specimens were cut from the rod. With a dimple grinder (Gatan Model 656, Gatan), mechanical polishing was performed to form a concave dimple (central disk thickness: approx. $20 \mu \mathrm{m}$ ) on the disk. After the disk sample was attached and reinforced on a Mo monohole mesh, it was finely thinned using a precision $\mathrm{Ar}$ ion polishing system (Gatan PIPS 691, Gatan) for TEM observation of the microstructure. The specimens were irradiated by an argon ion beam with an accelerating voltage of $4 \mathrm{kV}$ at a low incident angle of $4^{\circ}$. The ion beam module was used in a perpendicular direction to the interface for $\mathrm{Ar}$ ion irradiation.

\section{TEM observation and EDX analysis}

TEM observation and EDX analysis were performed using a high-resolution transmission electron microscope (HRTEM) (JEM-2010 HT, JEOL, Tokyo, Japan) at an accelerating voltage of $200 \mathrm{kV}$. Since the detector window of the EDX instrument (Oxford LINK ISIS, Oxford Instruments, Oxford, UK) was made of a thin organic film, it was possible to detect elements that were heavier than boron (B).

\section{RESULTS}

Figure 1 shows the microstructure of the gold sputter-coated titanium (CG). A sputtered gold layer (approx. $100 \mathrm{~nm}$ thick) was present on the titanium surface which seemed like thin amorphous titanium layer. EDX analysis at the $\mathrm{C}$ area in Fig. 1(b) (i.e., magnified B area) indicated pure titanium (Fig. 1(c)).

Figure 2 shows another CG specimen which was a more representative sample with a gold layer approximately $1 \mu \mathrm{m}$ thicker than the CG sample shown in Fig. 1. The underlayer of gold coating disappeared above the titanium surface. EDX analyses at C (near the Ti surface), D (several hundreds of $\mathrm{nm}$ inside the Ti surface), and $\mathrm{E}$ (approx. $3 \mu \mathrm{m}$ inside the Ti surface) are shown in (c), (d), and (e), respectively. The amount of oxygen decreased from the Ti surface toward the inside $(\mathrm{c} \rightarrow \mathrm{d} \rightarrow \mathrm{e})$. Aluminum was found in all areas.

Figure 3 shows a low-magnification microstruture

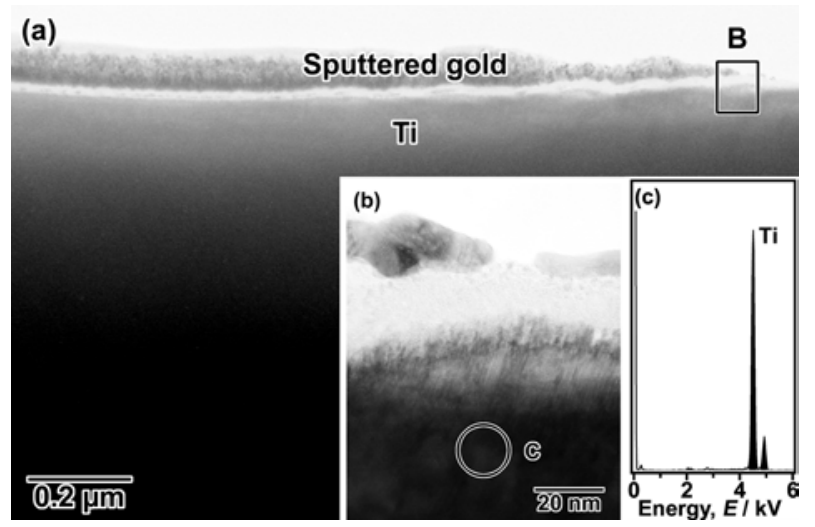

Fig. 1 (a) and (b): Microstructures of Au sputter-coated titanium (CG); and (c): EDX analysis. 


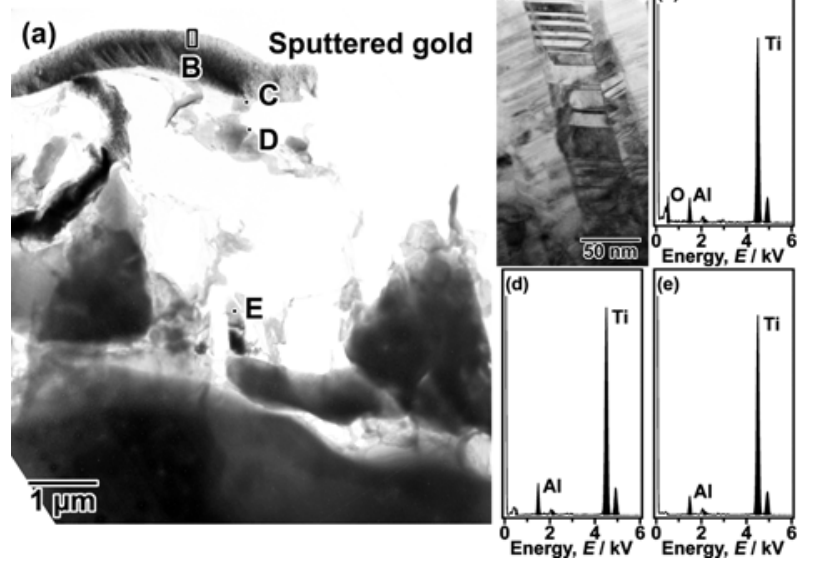

Fig. 2 (a) and (b): Another specimen of Au sputter-coated titanium (CG); and (c)-(e): EDX analyses.

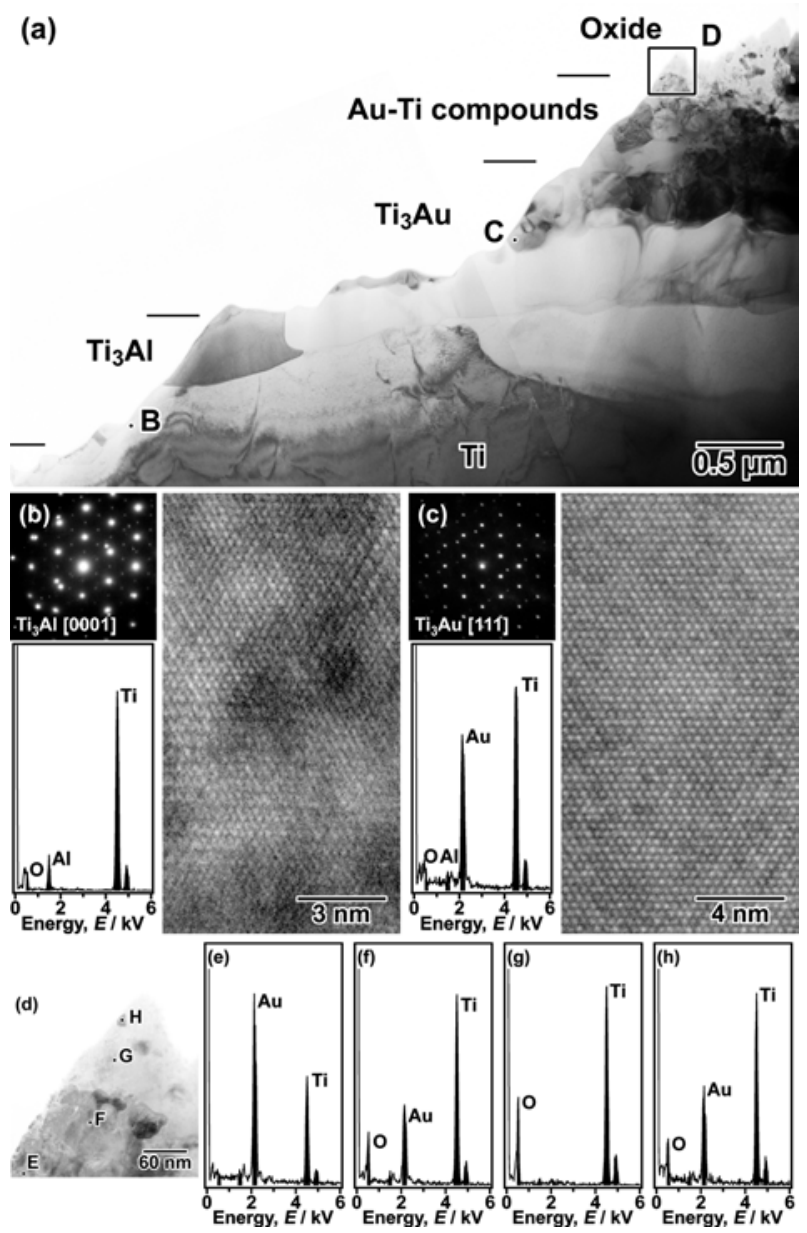

Fig. 3 Microstructure of Au sputter-coated and degassed titanium (CGD). (a): Low-magnification microstructure; (b) and (c): high-magnification microstructure, diffraction patterns and EDX analyses of $\mathrm{B}$ and $\mathrm{C}$ in (a); (d): high-magnification microstructure of $\mathrm{D}$ in (a); and (e)-(h): EDX analyses of D in (a).
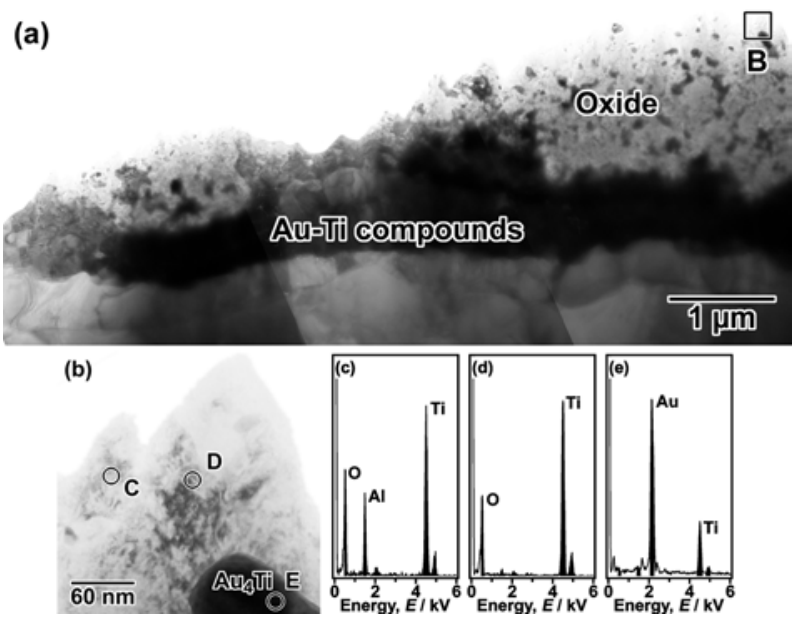

Fig. 4 (a): Low- and (b): high-magnification microstructures; and (c)-(e): EDX analyses of Au-Ti intermetallic compounds and surface oxide layer (CGD).

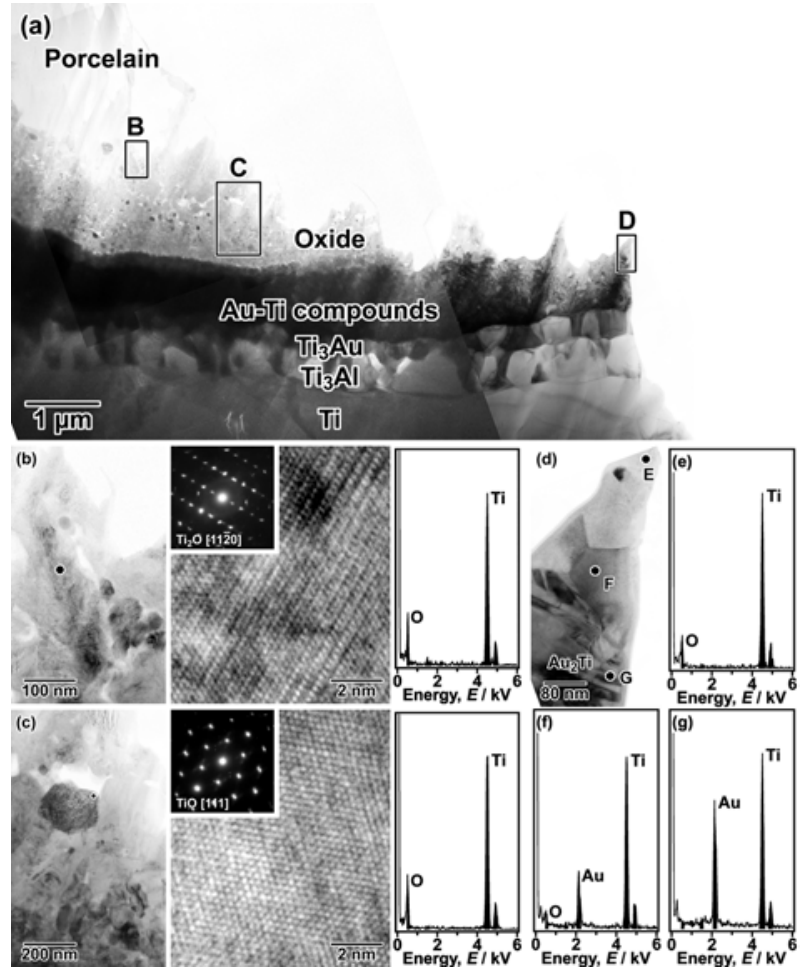

Fig. 5 Microstructures and EDX analyses of porcelainfused-to-titanium specimen (CGDP). (a): Lowmagnification microstructure; (b) and (c): highmagnification microstructures, diffraction patterns, high-resolution images, and EDX analyses of B and C in (a); (d): highmagnification microstructure of $\mathrm{D}$ in (a); and (e)-(g): EDX analyses of D in (a). 
of the gold sputter-coated Ti after degassing (CGD). The gold-coated layer produced Au-Ti intermetallic compounds, oxides (above the compounds), and $\mathrm{Ti}_{3} \mathrm{Au}$ and $\mathrm{Ti}_{3} \mathrm{Al}$ layers (beneath the compounds) after degassing. Diffraction patterns of areas $\mathrm{B}$ and $\mathrm{C}$ in Fig. 3(a) correspond with Figs. 3(b) and 3(c). At B, $\mathrm{Ti}_{3} \mathrm{Al}$ had an ordered hexagonal-closed-packed (hcp) structure $\left(\mathrm{DO}_{19}\right.$-type ordered structure), whereas $\mathrm{Ti}_{3}$ $\mathrm{Au}$ at $\mathrm{C}$ was an A15-type cubic structure. Oxygen was also dissolved to a certain degree in each structure. Figure 3(d) shows the microstructure and EDX analysis of the surface oxide layer starting with the $\mathrm{Au}-\mathrm{Ti}$ intermetallic compounds (area D in Fig. 3(a)). The ratio of $\mathrm{Au}$ and $\mathrm{Ti}$ varied in each place, and there were complex contents composed of Ti oxides and/or Au-Ti intermetallic compounds. Figure 4 further shows the low-magnification microstructure and EDX analysis of the Au-Ti intermetallic compounds and surface oxide layer of the CGD sample. The surface oxide layer was composed of complex compounds including $\mathrm{Al}-\mathrm{Ti}$ oxide, titanium oxide, and $\mathrm{Au}_{4} \mathrm{Ti}$ phase.

Figures 5(a)-(c) display the microstructure and EDX analyses of a porcelain-fused-to-titanium specimen (CGDP). $\mathrm{Ti}_{3} \mathrm{Au}$ and $\mathrm{Ti}_{3} \mathrm{Al}$ layers were also observed beneath the Au-Ti intermetallic compound layer as in the CGD specimen (Fig. 5(a)). There was good adhesion of porcelain to the Au-Ti compound and $\mathrm{Ti}$ oxides without any gaps. EDX analyses of areas $\mathrm{B}$ and $\mathrm{C}$ in Fig. 5(a) show low-valence titanium oxides, $\mathrm{Ti}_{2} \mathrm{O}$ and $\mathrm{TiO}$, in Figs. 5(b) and (c). Figure 5(d) shows the EDX analysis of area D in Fig. 5(a), which was the interface between $\mathrm{Au}$-Ti intermetallic compounds and oxide layer on the porcelain side. The phase formation gradually changed from an oxide (titanium oxide) to an intermetallic compound $\left(\mathrm{Au}_{2} \mathrm{Ti}\right)$; in addition, oxygen concentration for $\mathrm{Ti}(-\mathrm{O})$ was quite low.

\section{DISCUSSION}

Beneath the sputtered gold layer of the specimens, there was a layer (CG; Fig. 2) with a structure similar to the structure observed in a porcelain-titanium specimen that included a Ti-deficient intermediate layer ${ }^{15)}$. The amount of oxygen $(\mathrm{c} \rightarrow \mathrm{d} \rightarrow$ e) also decreased from the Ti surface to the inside, similar to the results obtained from the porcelain-fused-totitanium specimens ${ }^{15)}$. However, the oxygen distribution observed in the CG specimen might be originally derived from the interaction between the investment material and molten titanium during the casting procedure. This was particularly so because the CG samples did not undergo any heat processes such as degassing or porcelain fusing, which would otherwise introduce oxidation on the surface. In the same vein, aluminum - which was believed to be derived from the investment material - was detected throughout the specimen. It was interesting that the aluminum diffused more deeply into the interior than did the dissolved oxygen. This phenomenon was also reported in a previous study ${ }^{18)}$ investigating the surface reaction layers of titanium cast into molds containing investment materials $\left(\mathrm{MgO}-\mathrm{Al}_{2} \mathrm{O}_{3}\right.$ spinel) similar to that used in this study.

The gold sputter-coated and degassed titanium specimen (CGD) had a much more complicated microstructure, which included layers of $\mathrm{Au}-\mathrm{Ti}$ intermetallic compounds, $\mathrm{Ti}_{3} \mathrm{Au}$, and $\mathrm{Ti}_{3} \mathrm{Al}$ (Figs. 3(a)(c)). The border of the Au-Ti intermetallic compound layer and the surface oxide layer also had a complex microstructure comprising $\mathrm{Au}-\mathrm{Ti}$ (-O) intermetallic compounds, Ti oxide, and Al-Ti oxide (Figs. 3(d) and 4). In fact, various $\mathrm{Ti}-\mathrm{Au}$ intermetallic compounds are found in the Ti-Au phase diagram ${ }^{19}$. Therefore, the Ti-Au intermetallic compounds in the CGD sample could be composed of several Ti-Au crystal structure phases such as AuTi, $\mathrm{Au}_{2} \mathrm{Ti}$, and $\mathrm{Au}_{4} \mathrm{Ti}$, although not all the phases were confirmed in this study.

Interestingly, no rutile-type $\mathrm{TiO}_{2}$ phase with columnar crystal structure was observed in any layer or any area in this study. In our previous study ${ }^{20)}$, the formation of a rutile-type $\mathrm{TiO}_{2}$ phase with columnar crystal structure was observed in the degassed titanium specimen as a surface oxide layer, which disappeared after the porcelain was fused ${ }^{14)}$. This process was believed to occur because of titanium diffusion from the titanium surface toward the porcelain during fusing. Hence, the formation of $\mathrm{Au}-\mathrm{Ti}$ intermetallic compounds in the CGD sample after degassing might have suppressed titanium diffusion during the degassing step as well as in the subsequent porcelain fusing step.

In our previous studies ${ }^{14,15)}$, the porcelain-fused-totitanium specimens without gold coating produced a Ti-deficient intermediate layer composed of amorphous titania and highly oxygen-dissolved titanium on the titanium side; this layer was considered to be a cause of cohesive failure at the interface. The gold-coated titanium specimen (CGDP; Fig. 5(a)) in this study did not have a Ti-deficient intermediate layer. Besides, there was fairly close contact between porcelain and titanium via the $\mathrm{Ti}_{3} \mathrm{Au}$ and $\mathrm{Ti}_{3} \mathrm{Al}$ phases under the Ti-Au intermetallic compound layer. (Note that the $\mathrm{Ti}_{3} \mathrm{Au}$ and $\mathrm{Ti}_{3} \mathrm{Al}$ phases with the $\mathrm{Ti}$ $\mathrm{Au}$ intermetallic compounds were also observed in the gold-coated, degassed titanium specimens (CGD)). These results suggested that gold sputter coating suppressed the formation of a Ti-deficient intermediate layer and contributed to the adhesion between the titanium and porcelain. Suppression of the formation of a Ti-deficient intermediate layer might have occurred because of the great affinity between 
$\mathrm{Au}$ and $\mathrm{Ti}$, which produced the Ti-Au intermetallic compounds and $\mathrm{Ti}_{3} \mathrm{Au}$ phase. These observations were in agreement with a study by Miura et $a l .{ }^{17}$, in which it was reported that the formation of Ti-Au compounds diminished the Ti-deficient intermediate layer as well as cracks and crevices observed in the layer, thereby contributing to improved adhesion between the titanium and porcelain. In addition, these findings corroborated the results obtained by Lee et $a l$. who reported that porcelain adherence to cast titanium could be improved by gold sputter coating ${ }^{16)}$.

\section{CONCLUSIONS}

This study investigated the interfacial microstructure between gold sputter-coated titanium and low-fusing porcelain by means of TEM. Gold sputter coating on the titanium surface produced a Ti-Au intermetallic compound layer at the interface after degassing and porcelain fusing, and suppressed the formation of an intermediate layer consisting of an amorphous titanium oxide, which was considered to be a cause of cohesive fracture at the porcelain-titanium interface without gold coating. It appeared that the Au layer worked as a diffusion barrier to oxygen and titanium. Moreover, the porcelain adhered well to the titanium substrate through the $\mathrm{Au}-\mathrm{Ti}$ compound layer.

\section{ACKNOWLEDGEMENTS}

This study was supported by a grant from NIH/NIDCR, No. DE11787. Editorial assistance by Mrs Jeanne Santa Cruz is also much appreciated.

\section{REFERENCES}

1) Walter M, Reppel PD, Boning K, Freesmeyer WB. Six-year follow-up of titanium and high-gold porcelain-fused-to-metal fixed partial dentures. J Oral Rehabil 1999; 26:91-96.

2) Miura I, Ida K. Dental use of titanium. In: Dental applications of titanium, Quintessence Publishing Co., Tokyo, 1988, pp.198-212.

3) Suansuwan N, Swain MV. New approach for evaluating metal-porcelain interfacial bonding. Int $\mathrm{J}$ Prosthodont 1999; 12:547-552.

4) Kimura H, Horng CJ, Okazaki M, Takahashi J. Oxidation effects on porcelain-titanium interface reaction and bond strength. Dent Mater J 1990; 9:91-99.

5) Derand T, Herø H. Bond strength of porcelain on cast vs. wrought titanium. Scand J Dent Res 1992; 100:184-188.

6) Hautaniemi JA, Herø H, Juhanoja JT. On the bonding of porcelain on titanium. J Mater Sci Mater Med 1992; 3:186-191.

7) Watanabe K, Okawa S, Miyagawa O, Nakano S, Honma H, Shiokawa N, Kobayashi M. Interface reactions between titanium and porcelain during firing. J J Dent Mater 1993; 12:620-629.

8) Hanawa T, Kon M, Ohkawa S, Asaoka K. Diffusion of elements in porcelain into titanium oxide. Dent Mater J 1994; 13:164-173.

9) Pang I, Gilbert J, Chai J, Lautenschlager EP. Bonding characteristics of low-fusing porcelain bonded to pure titanium and palladium-copper alloy. J Prosthet Dent 1995; 73:17-25.

10) Pröbster L, Maiwald U, Weber H. Three-point bending strength of ceramics fused to cast titanium. Eur J Oral Sci 1996; 104:313-319.

11) Wang RR, Fung KK. Oxidation behavior of surfacemodified titanium for titanium-ceramic restorations. J Prosthet Dent 1997; 77:423-434.

12) Yilmaz H, Dincer C. Comparison of the bond compatibility of titanium and an $\mathrm{NiCr}$ alloy to dental porcelain. J Dent 1999; 27:215-222.

13) Miura E, Liu J, Watanabe I, Tanaka Y, Shiraishi T, Hisatsune K, Atsuta M. Determination of peeling plane of the fused porcelain to titanium. $\mathrm{J} J$ Inst Metals 2001; 65:819-822.

14) Tanaka Y, Watanabe I, Shiraishi T, Hisatsune K. Structure of the interface between titanium and fused porcelain. Materia 2000; 39:995.

15) Tanaka Y, Watanabe I, Miura E, Shiraishi T, Hisatsune K. Nanostructure analysis on the metalbond-porcelain using titanium by TEM and EELS. In: Proceedings of the $4^{\text {th }}$ Pacific Rim International Conference on Advanced Materials and Processing (PRICM4), The Japan Institute of Materials, 2001; pp.265-268.

16) Lee KM, Cai Z, Griggs JA, Guiatas L, Lee DJ, Okabe T. SEM/EDS evaluation of porcelain adherence to gold-coated cast titanium. J Biomed Mater Res 2004; 68B:165-173.

17) Miura E, Tabaru T, Liu J, Tanaka Y, Shiraishi T, Hisatsune K. Effect of gold coating on interfacial reaction between dental porcelain and titanium. J Inst Metals 2006; 70:51-58.

18) Miyakawa O, Watanabe K, Okawa S, Nakano S, Kobayashi M. Reaction layers of titanium cast in molds containing spinel. J Jpn Dent Mater 1995; 14:560-568.

19) Massalski TB. Binary alloy phase diagrams, 2nd ed, ASM International, Materials Park, Ohio, 1992, pp.442-445.

20) Tanaka Y. Titanium-oxide interface structures formed by degassing and anodization processes. J Mater Sci 2005; 40:3081-3090. 